\title{
Research on the Flow Resistance Coefficient of a Multi-Hole, Secondary Pressure-Reducing Sleeve Valve
}

Dong-tao Xu ( $\sim$ as_xudongtao@163.com )

University of science and technology Liaoning https://orcid.org/0000-0002-1565-8644

Chang-rong Ge

University of science and technology Liaoning

Xiang-rui Meng

University of Science and Technology Liaoning

Shu-fang Xu

University of Science and Technology Liaoning

Xiao-guang Yu

University of Science and Technology Liaoning

Original Article

Keywords: Flow resistance coefficient, flow characteristics, regulating valve, flow rate test

Posted Date: May 28th, 2020

DOI: https://doi.org/10.21203/rs.3.rs-30236/v1

License: (c) (1) This work is licensed under a Creative Commons Attribution 4.0 International License. Read Full License 


\section{Abstract}

To solve the problem of valve noise, a multi-hole sleeve valve with secondary pressure-reducing function is presented in this paper. During the flow design of the valve, the flow resistance coefficient of the valve served as an important parameter. Because of two pressure-reducing components assembled to a multihole sleeve valve, the flow resistance coefficient of the valve changed. Thus, correction of the flow resistance coefficient had to be affected. In this paper, the relationship between the flow rate and flow resistance coefficient of the valve was first mapped and established. Then, the flow rate of the sleeve was obtained using SolidWorks simulation software. Locally refined finite element mesh technology was applied to the simulation to improve simulation accuracy. A parallel flow test platform for the regulating valve was established, and the flow rate of the multi-hole sleeve valve was detected at different openings, thus, verifying the reliability of the numerical simulation results. Finally, the simulation flow rate of the valve at different openings was substituted into the mapping relationship formula, in this way, the flow resistance coefficient of the sleeve valve was obtained. By using the modified flow resistance coefficient, the flow rate characteristics of the multi-hole, secondary pressure-reducing sleeve valve were efficiently and accurately established.

\section{Introduction}

A regulating valve is a control composite that assists in controlling the flow rate, throttling, and stabilizing pressure in a control system ${ }^{[1-3]}$. In recent years, alongside the development of science and technology, the requirements for the performance of regulating valves have also continuously improved.

Environmental protection requirements, particularly reducing noise pollution of the regulating system, have also been put forward. When fluid flows through the throttle hole of the regulating valve, as the flow area decreases, the flow velocity increases, and the pressure difference between the two sides of the throttle holes rises. This can cause significant noise and effect damage to control equipment ${ }^{[4-5]}$.

The sleeve valve ${ }^{[6-7]}$ is a specially structured regulating valve. The valve plug moves up and down in a cylindrical sleeve to change the flow area, thereby controlling the flow rate of the valve. To control and reduce pressure difference and noise, the throttle holes of sleeve valves have been designed as the labyrinth ${ }^{[8-9]}$, window ${ }^{[10]}$ and multi-hole types ${ }^{[11]}$. However, the labyrinth throttle hole type significantly restricts flow rate. The window-type sleeve valve has a poor noise reduction ability. In this paper, a multihole sleeve valve with a secondary pressure-reducing function is presented. A set of pressure-reducing components were assembled inside and external to the throttle holes, respectively, so that it had low noise, good dynamic stability, and other advantages. However, when we designed the flow characteristics of the valve, the flow channel and the pressure-reduction components had a significant impact on the flow resistance coefficient. A large error occurred when we employed a traditional flow resistance coefficient to calculate the flow rate at different openings. However, calculating using the finite element method, or simulation method, can be very complex. Additionally, each simulation required significant time to complete and hardware with powerful computational capabilities. As such, it was necessary to 
establish an efficient theoretical method to design the flow rate of the multi-hole, secondary pressurereducing sleeve valve. In the theoretical calculation process, the flow resistance coefficient of the valve directly affected the calculation accuracy.

Accordingly, in this paper, the flow rate of the valve at each opening was obtained by numerical simulation. The simulation results were verified using a flow rate test. Then, the simulation flow rate was substituted into the mapping relationship equation between the flow rate and the flow resistance coefficient of the valve. In this manner, the flow resistance coefficient of the sleeve valve was obtained. The modified flow resistance coefficient can be used to design this type of valve with different flow and diameter characteristics.

\section{Structural Description Of The Multi-hole, Secondary Pressure- reducing Sleeve Valve}

The structure of the multi-hole secondary pressure-reducing sleeve valve is shown in Fig. 1.

1- the valve body, 2- the valve seat with noise reduction cage, 3- external noise reduction cage, 4- multihole sleeve

5- pressure cage, 6-valve plug, 7-valve rod, 8- bonnet.

It included eight major components: the valve body, the valve seat with noise reduction cage, external noise reduction cage, multi-hole sleeve, pressure cage, valve plug, valve rod, and a bonnet. The outer surface of the valve plug and the inner surface of the multi-hole sleeve represented fitted surfaces. Under the action of the external actuator, the valve rod was able to drive the valve plug to move up and down, in this manner, the throttle holes on the multi-hole sleeve were exposed to form an effective fluid area. The size and layout of these holes were able to realize the different flow characteristics of the regulating valve. When the pressure difference between the two sides of the throttle holes was large, flash evaporation and cavitation could occur ${ }^{[12-13]}$, giving rise to significant noise and vibration. To reduce the valve noise, a valve seat with a noise reduction cage and an external noise reduction cage was assembled on both sides of the multi-hole sleeve.

\section{Flow Calculation Of The Multi-hole, Secondary Pressure-reducing Sleeve Valve}

The flow rate through the throttle holes was calculated according to hydromechanics. Based on the thickness of the sleeve, the throttle holes on the multi-hole sleeve were typically thin-walled. These thinwalled holes were short with minimal frictional resistance. The flow rate was minimally affected by temperature and viscosity changes and, as such, was relatively stable.

The ideal fluid passed through a thin-walled hole, as shown in Figure 2. 
First, we assumed that fluid energy loss had been ignored when the fluid passed through the flow channel. According to the law of the conservation of energy, the total energy of the fluid at the inlet of the valve was equal to the total energy of the fluid at the outlet. In the cross-sections $\otimes$ and $\otimes$, according to the Bernoulli equation, the energy of the fluid can be expressed as follows:

$$
\frac{p_{1}}{\rho g}+\frac{\alpha_{1} v_{1}^{2}}{2 g}+h_{1}=h_{2}+\frac{p_{2}}{\rho g}+\frac{\alpha_{2} v_{2}^{2}}{2 g}+\xi \frac{v_{c}^{2}}{2 g}
$$

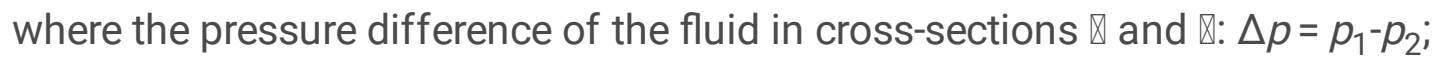

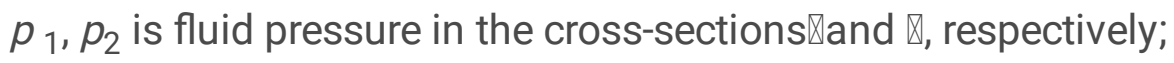

$h_{1}, h_{2}$ is the potential energy of the fluid in cross-sections $\otimes$ and $\otimes$, respectively;

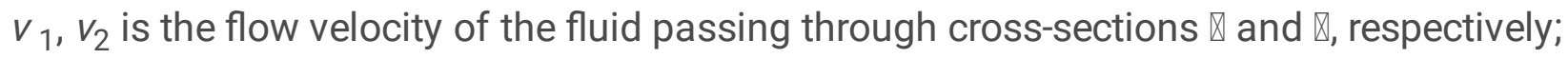

$\rho$ is the density of fluid;

$\xi$ is the flow resistance coefficient;

$a_{1}, a_{2}$ is the kinetic energy correction coefficient in cross-sections $\otimes$ and $\otimes$, respectively;

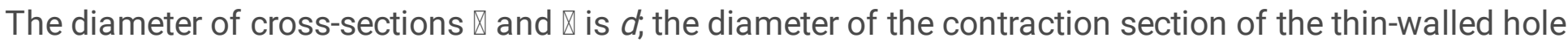
is $d_{0}$. Owing to $d » d_{0}$, thus, $v_{1} \approx 0$. When the fluid flowed through the contraction section of the thinwalled hole, the flow velocity was uniform, thus, $a_{1}=a_{2}=1$, and the fluid potential energy in crosssections $\otimes$ and $\otimes$ was equal, i.e., $h_{1}=h_{2}$.

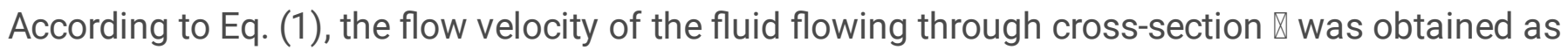
follows:

$$
v_{2}=\frac{1}{\sqrt{\xi}} \sqrt{\frac{2 \Delta p}{\rho}}
$$

2

The sectional area of the thin-walled hole is $A_{e}$ and the sectional area of cross-sections $\nabla a n d \mathbb{Z}$ is $A$. According to Eq. (2), the flow rate of the fluid passing through the hole was obtained as follows:

$$
q_{v}=A_{\varepsilon} v_{2}=\frac{A_{v}}{\sqrt{\xi}} \sqrt{\frac{2 \Delta p}{\rho}}
$$


Equation (3) shows the flow rate of the fluid through the sleeve valve was closely related to density $\rho$ of the fluid, effective flow area $A_{e}$, pressure difference $\Delta p$, and flow resistance coefficient $\xi$.

When the fluid flowed through the valve seat with the noise reduction cage, the external noise reduction cage, and the throttle hole of the multi-hole sleeve, their combined multi-hole structure caused part of the energy to be lost and reduced fluid pressure, changing the flow resistance coefficient. Accordingly, a large error will be observed when using traditional flow resistance coefficient $\xi$ to calculate the flow rate of the valve, which must be corrected.

\section{Flow Simulation Of The Multi-hole, Secondary Pressure-reducing Sleeve Valve}

\subsection{Establishing the simulation model}

Prior to the flow simulation calculation, a virtual simulation model of the multi-hole, secondary pressurereducing sleeve valve was created using SolidWorks software (2016), as shown in Fig. 2. The nominal diameter of the valve was $80 \mathrm{~mm}$.

Same-stepped holes were equally distributed around the valve seat and were also equally distributed on the external noise reduction cage. These small holes were prevent flash evaporation and cavitation, and could effectively reduce the pressure and noise caused by the fluid. The flow area of these holes had be $5 \%$ larger than that of the throttle holes when the sleeve valve was fully open. This enabled them to reduce pressure and noise caused by the fluid to a satisfactory degree, without affecting the flow rate of the sleeve valve.

1- the valve body, 2- the valve seat with noise reduction cage, 3- external noise reduction cage, 4- multihole sleeve

5- pressure cage, 6-valve plug, 7-valve rod, 8- bonnet.

\subsection{Finite element mesh}

The SolidWorks flow Simulation module was used to set the global finite element mesh to the highest level, as shown in Fig. 3.

\subsection{Boundary conditions and simulation settings}

Based on the definition of flow capacity $K v$ of the regulating valve ${ }^{[14-16]}$, the simulation boundary conditions were set. When the regulating valve was fully opened, pressure difference $\Delta p$ at the inlet and outlet of the valve was $100 \mathrm{KPa}$, and the fluid density was $1000 \mathrm{~kg} / \mathrm{m}^{3}$ (room temperature water); flow capacity $K v$ was the flow rate of fluid that passed through the valve in $1 \mathrm{~h}$. The pressure at the inlet of the 
valve was set to $201,325 \mathrm{~Pa}$, the pressure at the outlet was $101,325 \mathrm{~Pa}$, and the roughness of the inside surface of the valve body was Ra25. The insertion target was the volume flow rate through the crosssection of the valve outlet.

\subsection{The flow rate simulation analysis}

The above model was used to simulate the multi-hole, secondary pressure-reducing sleeve valve. Its flow capacity was $K v=38.06$. The maximum stroke of the valve plug was $38 \mathrm{~mm}$. The model of the valve that conformed to linear flow characteristics was tested in the simulation.

4.4.1 Static pressure distribution of the fluid inside the valve. When the valve was fully opened, the static pressure distribution cloud diagram of the internal fluid on the symmetrical section was obtained, as shown in Fig. 4.

4.4.2 Flow rate simulation of the valve. The volume flow at the outlet of the valve was monitored. Following the iterative calculation, the volume flow rate at an opening ranging from $10-100 \%$ was obtained.

The simulation flow rate was compared with the theoretical standard flow rate, which met the standard linear flow characteristics. The curve subsequently obtained is shown in Fig. 5.

The maximum error occurred at an opening of $10 \%$, the error value was $5.55 \%$, and the minimum error occurred at an opening of $100 \%$. At $90 \%$ and $100 \%$ openings, the flow rate of the valve was lower than the standard value, the flow of other openings was slightly larger than the standard value. The software simulation method was used to effectively verify whether the flow rate of the valve met the specified flow characteristics. However, following the mesh refinement, the number of finite element meshes increased sharply, and each calculation required an extended period to finish iteration prior to achieving convergence. Concurrently, hardware support with powerful computing capabilities was required. As such, using software simulations to design the valve flow rate presented some limitations.

\section{Test Analysis Of The Multi-hole, Secondary Pressure-reducing Sleeve Valve}

\subsection{Introduction to the test system}

1. 1. backwater pipe; 2. electric pressure control valve; 3. manual ball valve; 4 . test point of regulating valve;

2. 5. pressure gauge; 6.electromagnetic flowmeter; 7. diverging pipeline; 8. surge tank; 9. expansion joint;

3. 10. pipeline pump; 11. diverging pipeline;12. water storage tank

To test whether the regulating valve met the rated flow characteristics ${ }^{[17-18]}$, a parallel flow rate test system with recyclable fluid equipment was designed, as shown in Fig. 6. The system comprised a water 
storage tank, parallel multi-stage pump, a surge tank, parallel test area, and a backwater pipe. The parallel test area comprised multiple test pipelines connected in parallel, which were able to test the regulating valves with nominal diameter, ranging from DN15 to DN450. When a pipeline was active, the manual ball valves (3) at both ends of the remaining pipelines were closed. During the test, the regulating valve was connected to the position indicated by 4 in Fig. 6 . The pressure gauges (5) were set at the inlet and outlet of the tested regulating valve, and the data were transmitted to the computer. The computer controlled the pipeline pump (10) through the inverter to adjust the water pressure. If a greater pressure was required, several pipeline pumps could function simultaneously in parallel, as shown in Fig. 7. The electric pressure control valve (2) was set at both sides of the tested regulating valve to regulate the pressure at the inlet and outlet of the valve.

When the pressure difference met the requirements, the flow rate at different openings of the tested valve could be read from the electromagnetic flowmeter. The fluid of each test line was sent back to the water storage tank through the return pipe.

\subsection{Test data analysis}

The tested multi-hole, secondary pressure-reducing sleeve valve had the same parameters as the simulation model. The pressure difference between the inlet and outlet of the valve was $100 \mathrm{KPa}$. The flow rate of each opening from $10-100 \%$ was observed from the electromagnetic flowmeter, as shown in Table 1.

Table 1

Test flow rate at different

opening

\begin{tabular}{|llll|}
\hline $\boldsymbol{i}$ & $q_{v}$ & $\boldsymbol{i}$ & $q_{v}$ \\
$\%$ & $\mathrm{~m}^{3} / \mathrm{h}$ & $\%$ & $\mathrm{~m}^{3} / \mathrm{h}$ \\
\hline 10 & 4.30 & 60 & 25.07 \\
\hline 20 & 8.48 & 70 & 29.84 \\
\hline 30 & 13.25 & 80 & 33.27 \\
\hline 40 & 16.75 & 90 & 36.50 \\
\hline 50 & 20.60 & 100 & 39.57 \\
\hline
\end{tabular}

Table 1 shows that the flow characteristics of the multi-hole, secondary pressure-reducing sleeve valve essentially conformed to its linear characteristics. When the valve was fully open, the flow rate was $39.57 \mathrm{~m}^{3} / \mathrm{h}$, and its $K v$ was 39.57 , which was slightly higher than the rated flow rate of $K v=38.06$; the error was $4.30 \%$. The flow rate obtained from the test was compared with the flow rate of standard linear flow, and with the simulation flow rate, as shown in Fig. 8. 


\section{Correction Of The Flow Resistance Coefficient}

According to Eq. (3), the following equation was obtained:

4

$\xi_{i}=\frac{2 \Delta p A_{e i}^{2}}{\rho q_{i d}^{2}} \quad(i=1 \sim 10)$

where $\xi_{i}$ is the flow resistance coefficient of each opening;

$q_{v i}$ is the flow rate of each opening;

$A_{e i}$ is the flow area of the throttle holes of each opening.

$i$ is the opening, i.e., $i=1$ to 10 .

The pressure difference at the inlet and outlet of the valve can be given as $\Delta p=100 \mathrm{KPa}$, and the fluid density as $\rho=1000 \mathrm{~kg} / \mathrm{m}^{3}$ (room temperature water). According to Eq. (4), $q_{v i} A_{e i}$ and $\xi_{i}$ of the multi-hole, secondary pressure-reducing sleeve valve at different openings could be calculated, as shown in Table 2 .

Table 2

Numerical examples of different openings

\begin{tabular}{|llllllll|}
\hline $\boldsymbol{i}$ & $\boldsymbol{q}_{v}$ & $A_{e}$ & $\xi_{i}$ & $\boldsymbol{i}$ & $\boldsymbol{q}_{v}$ & $A_{e}$ & $\xi_{i}$ \\
$\%$ & $\mathrm{~m}^{3} / \mathrm{h}$ & $* 10^{-4} \mathrm{~m}^{3}$ & & $\%$ & $\mathrm{~m}^{3} / \mathrm{h}$ & $* 10^{-4} \mathrm{~m}^{3}$ & \\
\hline 10 & 4.74 & 1.81 & 3.78 & 60 & 23.31 & 6.70 & 2.14 \\
\hline 20 & 8.28 & 2.41 & 2.20 & 70 & 27.25 & 7.81 & 2.13 \\
\hline 30 & 12.39 & 3.57 & 2.15 & 80 & 30.78 & 8.80 & 2.12 \\
\hline 40 & 15.84 & 4.61 & 2.20 & 90 & 34.20 & 9.92 & 2.18 \\
\hline 50 & 19.52 & 5.58 & 2.12 & 100 & 37.94 & 11.05 & 2.20 \\
\hline
\end{tabular}

Table 2 indicates that at openings of $20-100 \%$, the flow resistance coefficient value $\xi$ of the multi-hole, secondary pressure-reducing sleeve valve was roughly 2.2 . At a $10 \%$ opening, the value of the flow resistance coefficient $\xi$ was 3.78. Both the simulation results and test data reflected that the flow resistance coefficient was larger and the flow rate smaller. Therefore, based on current study, the value of the flow resistance coefficient $\xi$ of the multi-hole, secondary pressure-reducing sleeve valve was determined as a constant value, i.e., 2.2. When we designed the flow rate of the valve, to avoid the flow rate at a $10 \%$ opening from being insufficient, the flow resistance coefficient could be increased 1.5 times, that is, this could be achieved by increasing the flow area. According to the above research, as long as the 
effective fluid area of the throttle holes was known, a multi-hole, secondary pressure-reducing sleeve valve conforming to different flow characteristics and different $C_{v}$ values could be obtained.

\section{Conclusions}

(1) It is concluded that the flow resistance coefficient of the valve was 3.3 at a $10 \%$ opening, and 2.2 at an opening ranging $20-100 \%$. By using the modified flow resistance coefficient, the multi-hole, secondary pressure-reducing sleeve valve could be designed more efficiently.

(2) Using the mesh refinement technology of the local space virtual model, the simulation of the flow rate of the multi-hole, secondary pressure-reducing sleeve valve was performed. Experiments verified that the error of the simulation results was within the allowable range. The simulation flow rates were also concluded as being reliable.

(3) A parallel flow rate test system with recyclable fluid equipment was designed. The system was able to test the flow rate of the regulating valves with different specifications. The ideal differential pressure data could be adjusted quickly during the test, and the test results were subsequently more reliable.

\section{Declarations}

\section{Availability of data and materials}

All data, models are available from the corresponding author by request.

\section{Acknowledgements}

We thank Mr. De-qing Zhang, from AnShan Bell Automatic Controlling Co., Ltd, for providing some test equipment.

\section{Authors' Contributions}

Dong-tao Xu and Chang-rong Ge conceived, designed the study and. Xiang-rui Meng and Shu-fang Xu did flow simulation analysis. Dong-tao Xu and Xiao-guang Yu performed the experiments. Dong-tao Xu and Chang-rong Ge wrote the paper. Xiang-rui Meng and Shu-fang Xu reviewed and edited the manuscript. All authors read and approved the final manuscript.

\section{Authors' Information}

Dong-tao Xu, born in 1975, is currently an associate professor at school of mechanical engineering \& automation, university of science and technology Liaoning, China. His main research interests include industrial robot and throttle design.

Chang-rong Ge, born in 1996, is currently a MS candidate at school of mechanical engineering \& automation, university of science and technology Liaoning, China. 
Xiang-rui Meng, born in 1996, is currently a MS candidate at school of mechanical engineering \& automation, university of science and technology Liaoning, China.

Shu-fang Xu, born in 1992, is currently a MS candidate at school of mechanical engineering \& automation, university of science and technology Liaoning, China.

Xiao-guang Yu, born in 1958, is currently a professor at school of mechanical engineering \& automation, university of science and technology Liaoning, China.

\section{Competing Interests}

The authors declare no competing financial interests.

\section{Funding}

The work presented in this paper was partially funded by China national natural science foundation (China; grant no. 51775257); Natural Science Foundation of Liaoning Province, China (China; grant no. 20180550836).

\section{Author Details}

School of Mechanical Engineering \& Automation, University of Science and Technology Liaoning, Liaoning Anshan 114051, China.

\section{References}

1. 1. Edward Lisowski, Grzegorz Filo. CFD analysis of the characteristics of a proportional flow control valve with an innovative opening shape[J]. Energy Conversion and Management. 123 (2016): 15-28.

2. 2. ZHANG Wei-zheng, YU Shu-rong, ZHANG Xi-heng, et al. Numerical simulation and experimental analysis of interior flow field in control valves[J]. Journal of Lanzhou University of Technology, 2008, 34(3): 65-68.

3. 3. PENG Jian,HE Shi-quan $₫$ Structural Optimization and Characteristic Research of Air-defense Regulating Valve Spool[J]. Chinese Hydraulics $\otimes$ Pneumatics, 2020, (1): 131-136ه

4. 4. Chen Fu-qiang, Ren Xiao-dong, Hu Bo, et al. Parametric analysis on multi-stage high pressure reducing valve for hydrogen decompression[J]. International Journal of Hydrogen Energy, 2019, 44(59): 31263-31274.

5. 5. Zaki, Khaled; Imam, Yehya; El-Ansary, Amgad. Optimizing the dynamic response of pressure reducing valves to transients in water networks[J]. Journal of water supply research and technologyaqua, 2019, 68(5): 303-312.

6. 6. Jin Zhi-jiang, Qiu Chang, Jiang Cheng-hang, et al. Effect of valve core shapes on cavitation flow through a sleeve regulating valve[J]. Journal of zhejiang university-science $A, 2020,21(1)$ : 1-14. 
7. 7. Wang Yan, Xu Xiaogang, Hu Jian, HAO Jiaoshan, WANG Ruoyu, LI Shuxun. Numerical simulation of flow field and research of flow characteristics of multi-stage cage control valve[J]. Automation in petro-chemical industry, 2013, 1(49): 50-53.

8. 8. WU Shimin1, ZHOU Weiqin, SHI Yuejuan, LI Mingbin, WANG Yanchang. Simulation of flow characteristics of internal flow field for labyrinth regulating valve based on CFX[J]. Machine tool \& hydraulics, 2014, 42(23): 127-130.

9. 9. TAO Guoqing, LIU Jianfeng, ZHANG Shaohua, et al. Numerical simulation on flow character of labyrinth type regulating valve[J]. Fluid machinery, 2014, 11(42): 50-53.

10. 10. Li Shuxun, Li Zhong, Zhou Aimin, et al. Optimization and test on throttle plate opening profile line of 3-way control ball valve[J]. Journal of Huazhong University of Science and Technology (Natural Science Edition), 2017, 45(2): 61-66.

11. 11. Liu Q, Ye JH, Zhang G, et al. Study on the metrological performance of a swirlmeter affected by flow regulation with a sleeve valve. Flow Measurement and Instrumentation, 67(2019):83-94.

12. 12. Liu Xiumei, Wu Zihong, Li Beibei, et al. Influence of inlet pressure on cavitation characteristics in regulating valve[J]. Engineering applications of computational fluid mechanics, 2020, 14(1): 40-48.

13. 13. Chern, Ming-Jyh; Hsu, Ping-Huang; Cheng, Yeuan-Jong; et al. Numerical Study on Cavitation Occurrence in Globe Valve[J]. Journal of energy engineering-ASCE, 2013, 139(1): 35 - 34.

14. 14. Berestovitskiy E G, Ermilov M A, Kizilov P, et al. Research of an influence of throttle element perforation on hydrodynamic noise in control valves of hydraulic systems $[\mathrm{J}] \otimes$ Procedia engineering, 2015, 106(2015): 284-295区

15. 15. LI Husheng, TIAN Xiaoqing, YANG Fangyuan. Coal-oil slurry valve control strategies under differential opening condition[J]. Fluid machinery, 2016, 44(11): 58-60+19.

16. 16. Li Shuxun, Kang Yunxing, Wang Tianlong, et al. Numerical Simulation on Jet Flow Characteristics of Pressure Drop Sleeve of Drain Regulating Valve[J]. Fluid Machinery, 2019, 47(12): $1005-0329$.

17. 17. Wang Jun, Du Guang-sheng, Wang Jing-ying, et al. The experiment and analysis of transitional flow in pipe.[J]

18. Journal of Hydrodynamics, 2016, 28(2): 313-318.

19. 18. Sun Bing, Yang Zhenhua, Quan Weili. Cold Flow Test Investigation on Modulation Property of Fluidic Vortex Valve[J]. Journal of Projectiles, Rockets, Missiles and Guidance, 2014, 34(6): 107-109.

\section{Figures}




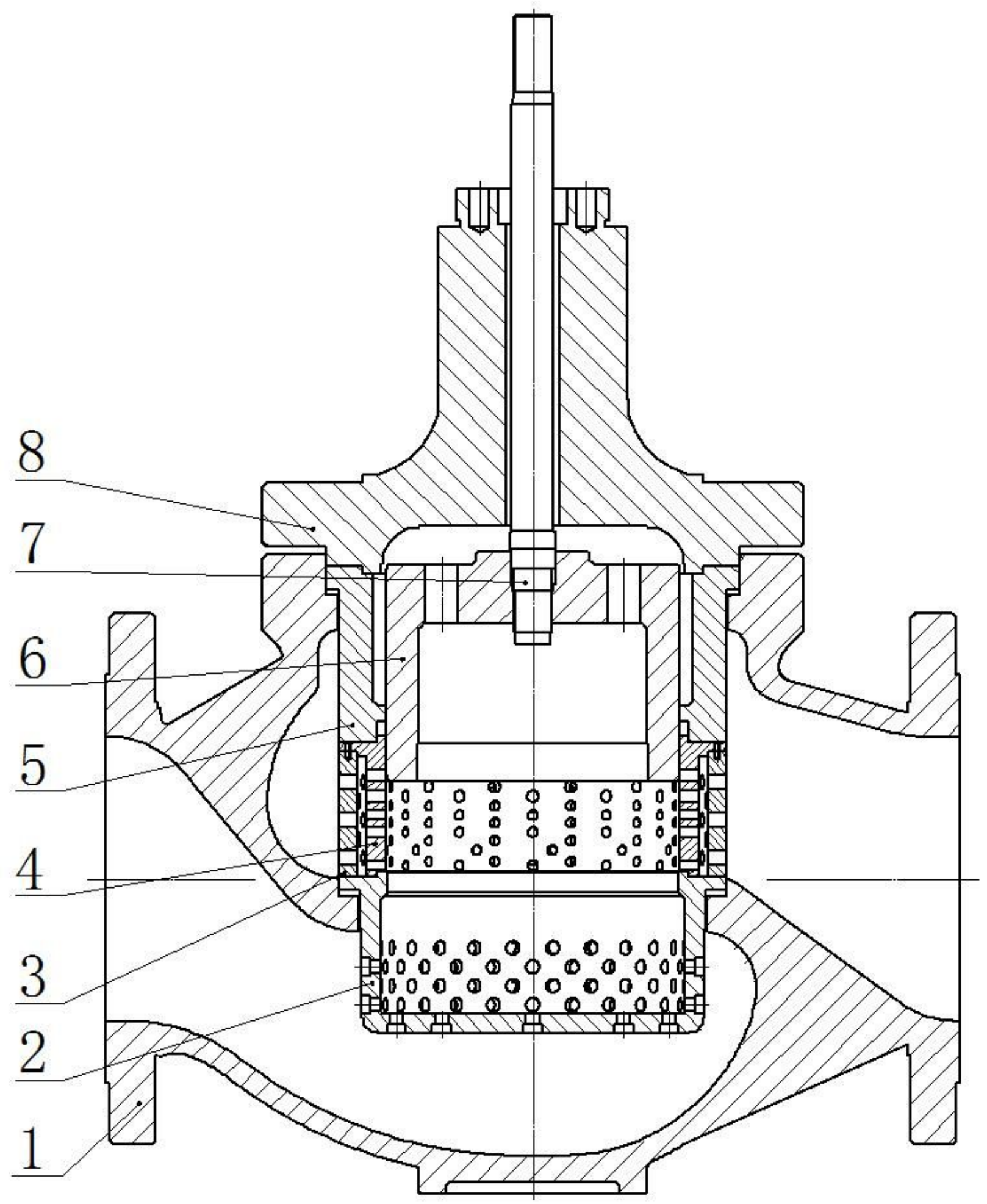

Figure 1

Figure 1. Multi-hole, secondary pressure-reducing sleeve valve 1- the valve body, 2 - the valve seat with noise reduction cage, 3- external noise reduction cage, 4- multi-hole sleeve 5- pressure cage, 6-valve plug, 7- valve rod, 8- bonnet. 


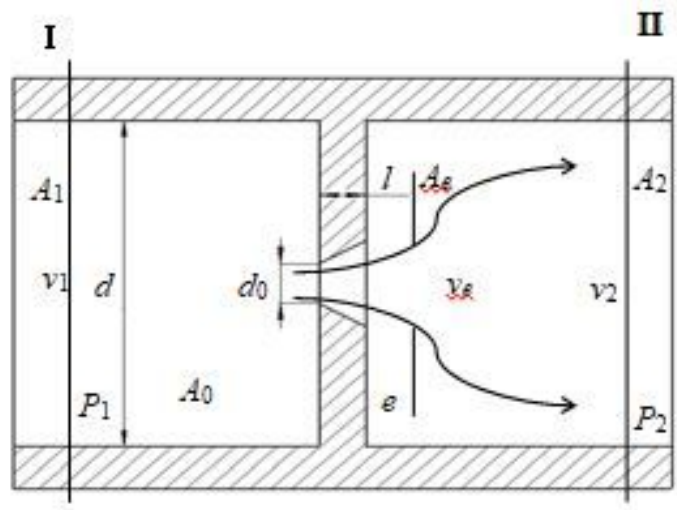

Figure 2

Fluid passing through thin-walled hole 


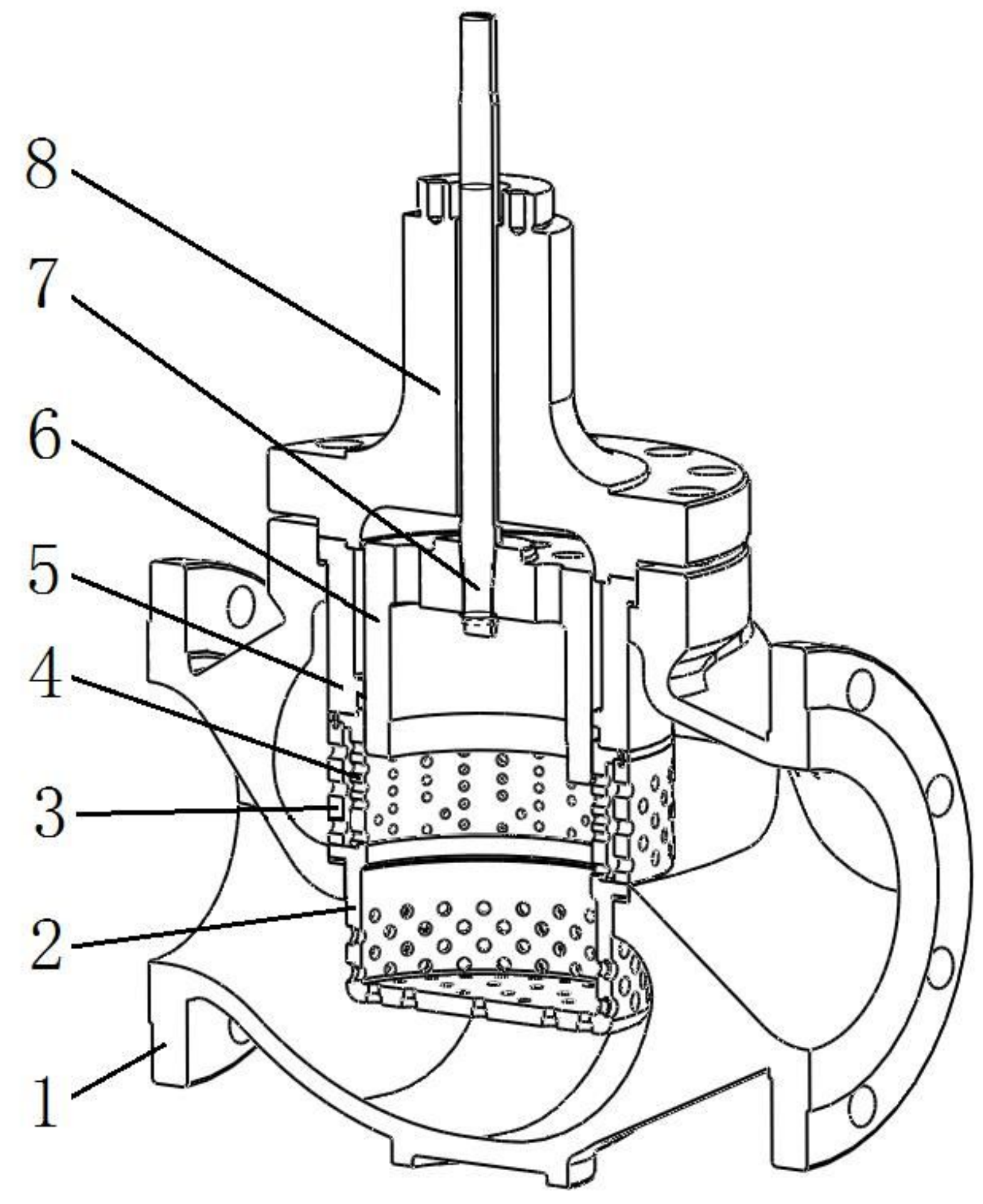

Figure 3

Simulation model of the multi-hole, secondary pressure-reducing sleeve valve 1- the valve body, 2- the valve seat with noise reduction cage, 3- external noise reduction cage, 4- multi-hole sleeve 5- pressure cage, 6-valve plug, 7-valve rod, 8- bonnet. 


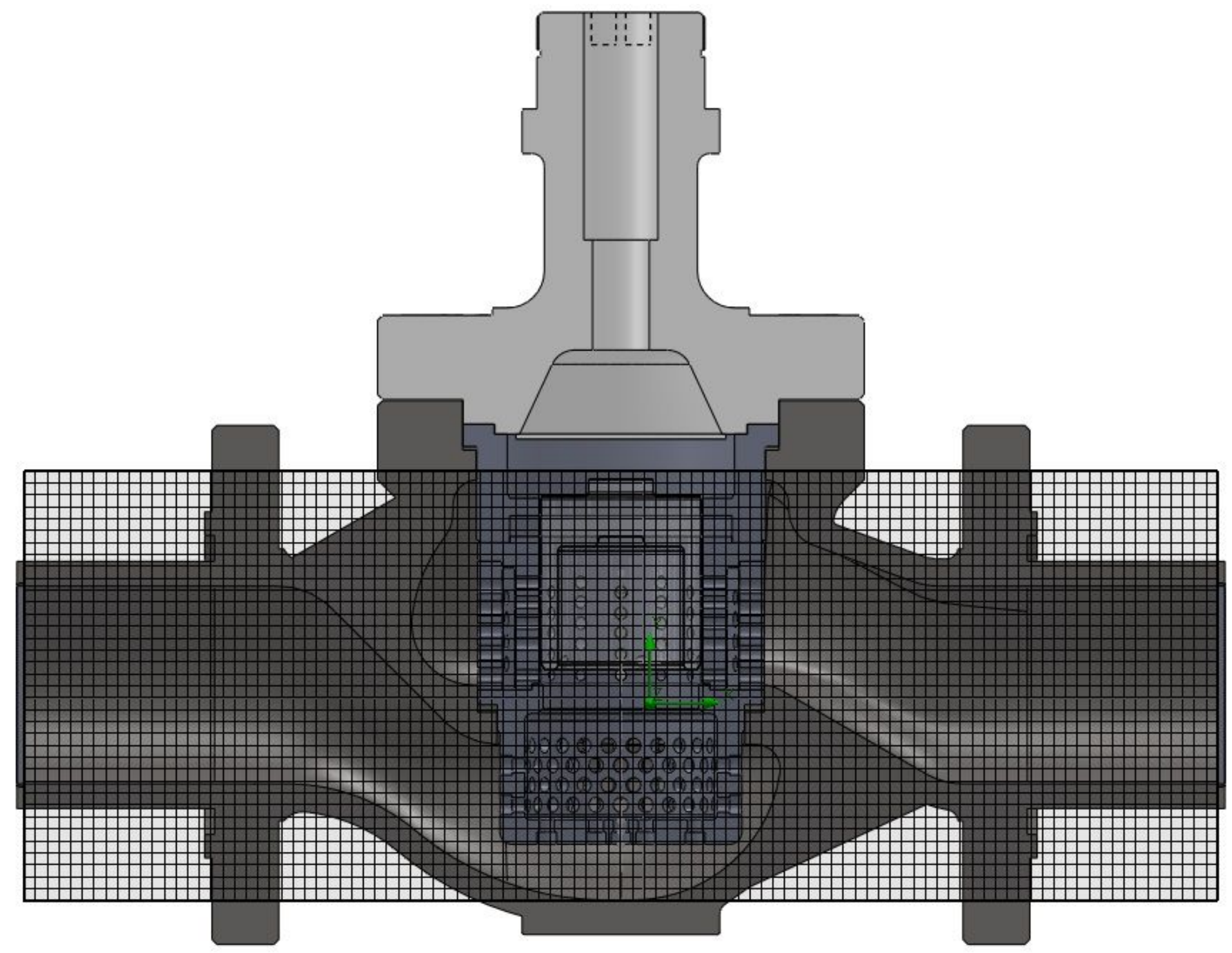

\section{Figure 4}

Finite element mesh of the model

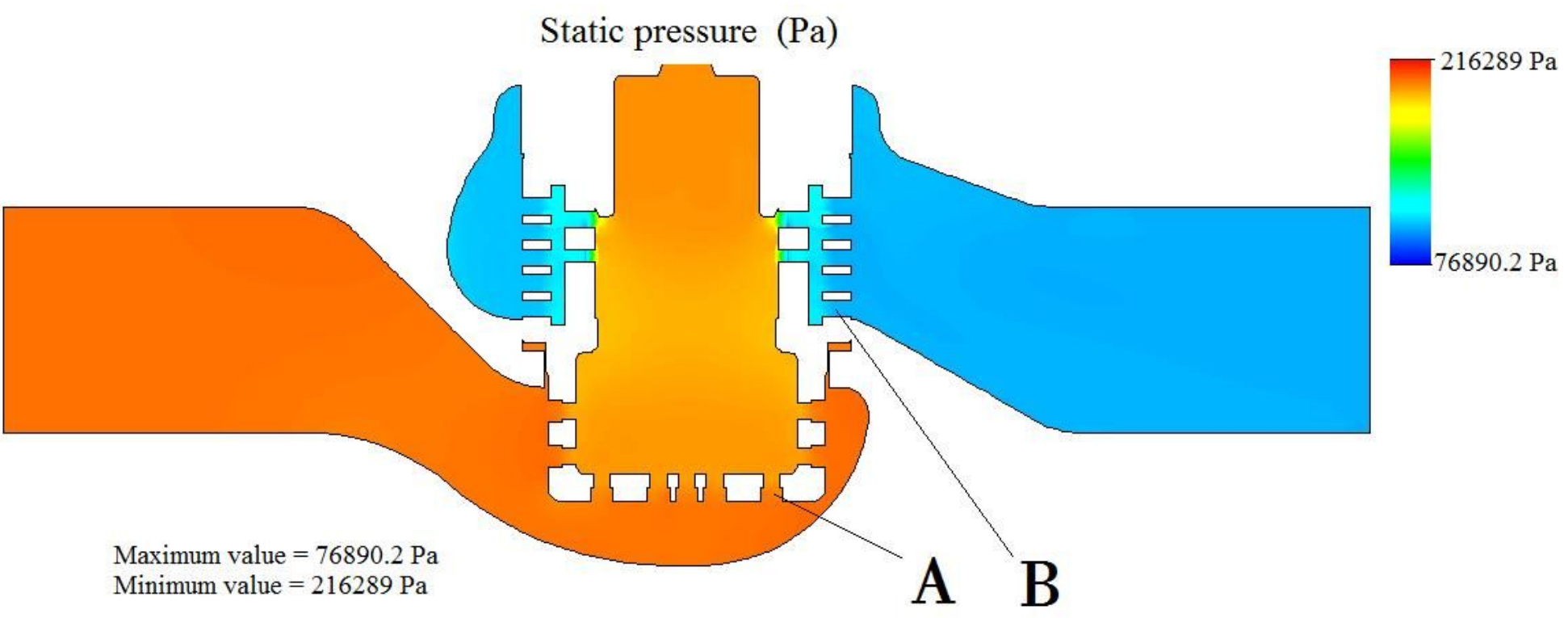


Figure 5

Cloud diagram of static pressure distribution

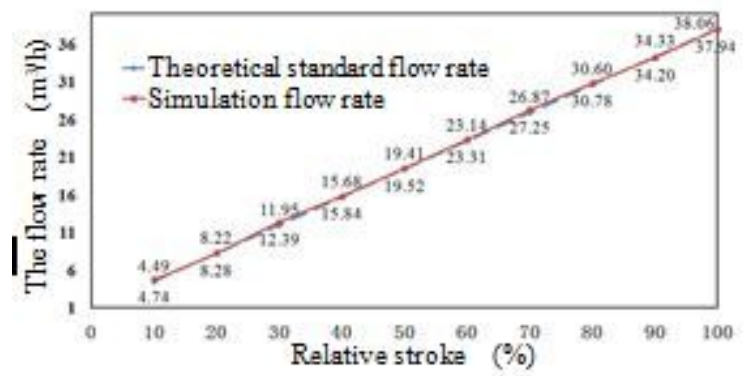

Figure 6

Comparison of simulated flow rate with standard data

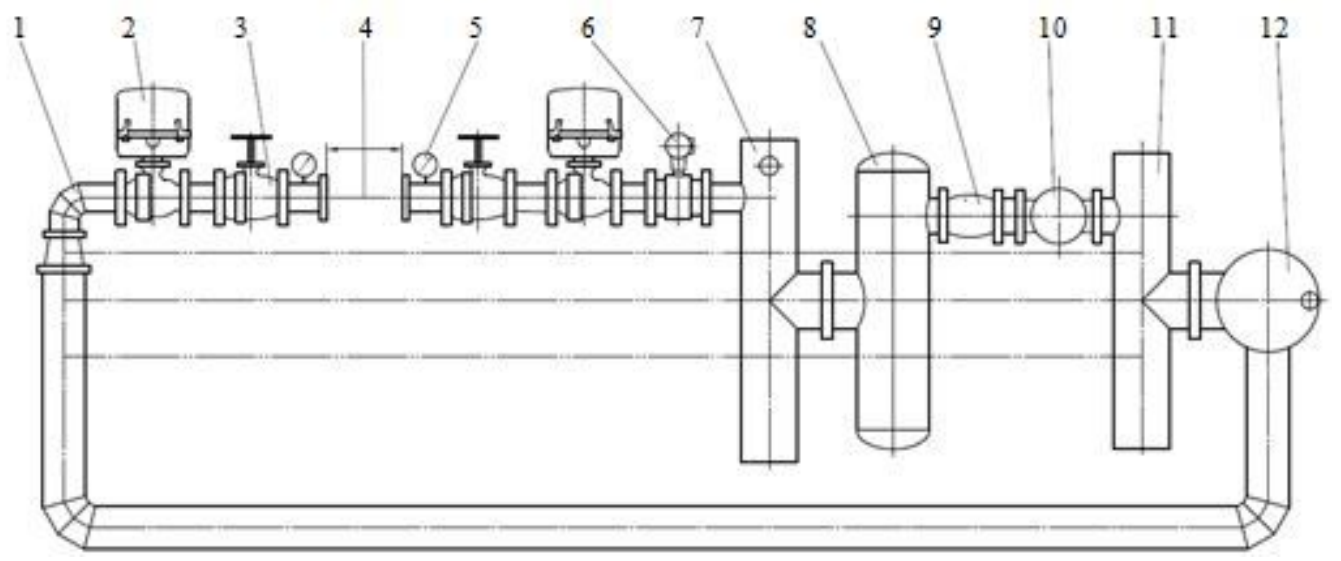

Figure 7

Regulating valve flow test system 1 . backwater pipe; 2 . electric pressure control valve; 3 . manual ball valve; 4 . test point of regulating valve; 5 . pressure gauge; 6 .electromagnetic flowmeter; 7 . diverging pipeline; 8. surge tank; 9. expansion joint; 10. pipeline pump; 11. diverging pipeline;12. water storage tank 


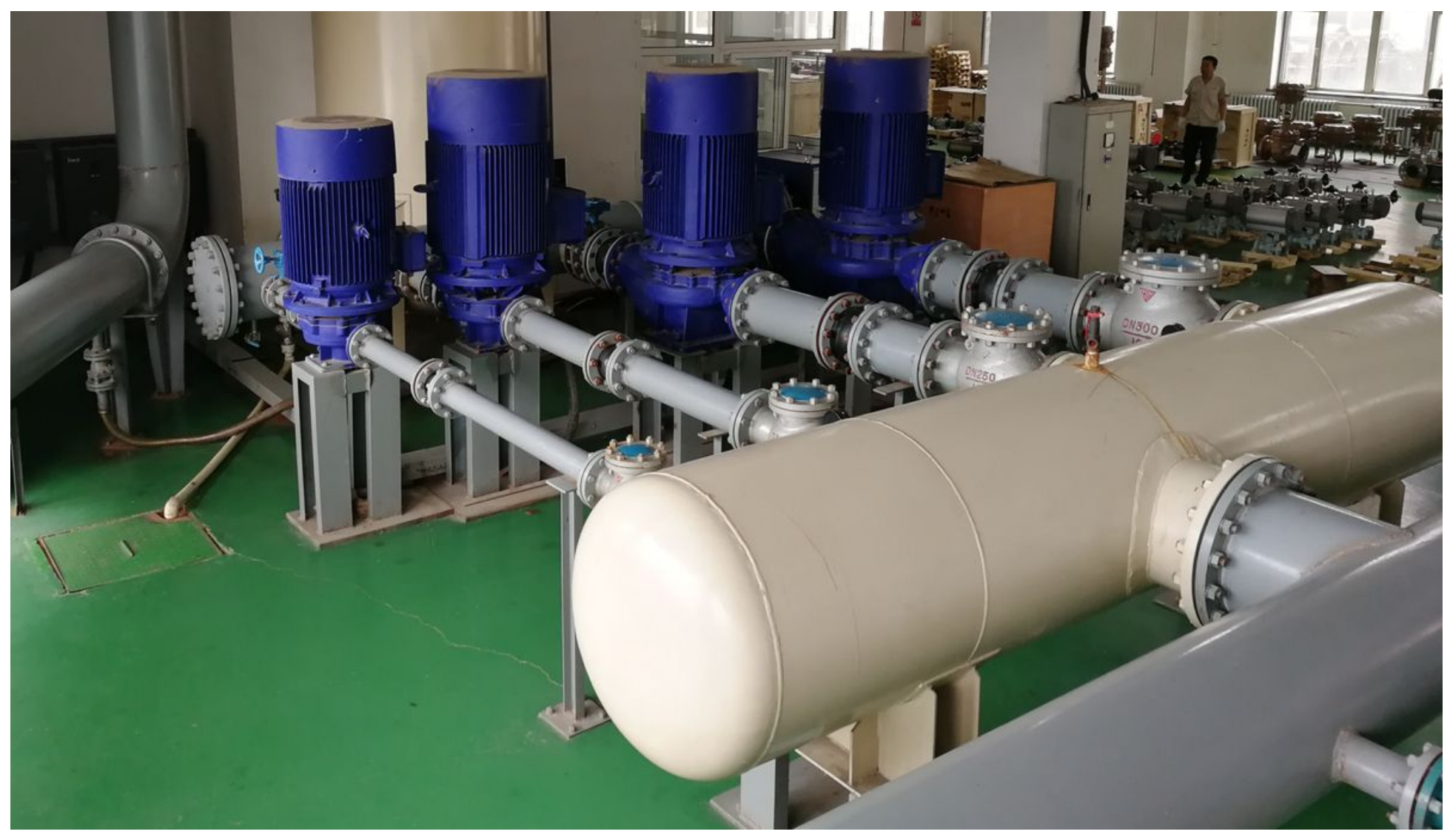

Figure 8

Pipeline pumps in parallel

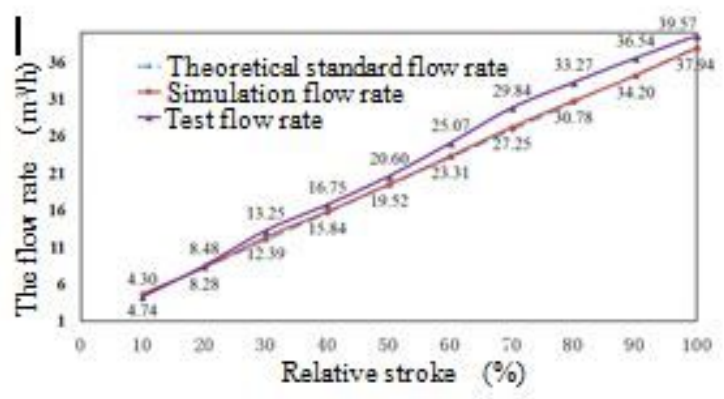

Figure 9

Comparison of the test flow rate with theoretical standard flow rate and simulation flow rate 